\title{
In-vivo flow simulation in coronary arteries based on computed tomography datasets feasibility and initial results
}

\section{Journal Article}

\section{Author(s):}

Frauenfelder, Thomas; Boutsianis, Evangelos; Schertler, Thomas; Husmann, Lars; Leschka, Sebastian; Poulikakos, Dimos; Marincek, Borut; Alkadhi, Hatem

Publication date:

2007

Permanent link:

https://doi.org/10.3929/ethz-b-000008532

Rights / license:

In Copyright - Non-Commercial Use Permitted

Originally published in:

European Radiology 17(5), https://doi.org/10.1007/s00330-006-0465-1 
Thomas Frauenfelder Evangelos Boutsianis Thomas Schertler Lars Husmann Sebastian Leschka Dimos Poulikakos Borut Marincek Hatem Alkadhi

\section{In-vivo flow simulation in coronary arteries based on computed tomography datasets: feasibility and initial results}

Received: 15 March 2006

Revised: 8 August 2006

Accepted: 25 August 2006

Published online: 24 October 2006

(C) Springer-Verlag 2006
T. Frauenfelder $(\bowtie) \cdot$ T. Schertler .

L. Husmann · S. Leschka ·

B. Marincek · H. Alkadhi

Department of Medical Radiology, Institute of Diagnostic Radiology, University Hospital Zurich,

Raemistrasse 100,

CH-8091 Zurich, Switzerland

e-mail: thomas.frauenfelder@usz.ch

Tel.: +41-1-2559383

Fax: +41-1-2554443

E. Boutsianis · D. Poulikakos Laboratory of Thermodynamics in Emerging Technologies, ETH Zurich, Zurich, Switzerland

\begin{abstract}
The purpose of this paper was to non-invasively assess hemodynamic parameters such as mass flow, wall shear stress (WSS), and wall pressure with computational fluid dynamics (CFD) in coronary arteries using patient-specific data from computed tomography (CT) angiography. Five patients (two without atherosclerosis, three with atherosclerosis) underwent retrospectively electrocardiogram (ECG) gated 16-detector row CT using ECG-pulsing and geometric models of coronary arteries were reconstructed for CFD analysis. Blood flow was considered laminar, incompressible, Newtonian, and pulsatile. The mass flow, WSS, and wall pressure were quantified and flow patterns were visualized. The wall pressure continuously decreased towards distal segments and showed pressure drops in stenotic segments. In coronary segments without atherosclerotic wall
\end{abstract}

changes, WSS remained low, even during phases of high flow velocity, whereas in atherosclerotic vessels, the WSS was elevated already at low flow velocities. Stenoses and post-stenotic dilatations led to flow acceleration and rapid deceleration, respectively, including a distortion of flow. Areas of high WSS and high flow velocities were found adjacent to plaques, with values correlating with the degree of stenosis. CFD provided detailed mass flow measurements. CFD analysis is feasible in normal and atherosclerotic coronary arteries and provides the rationale for further investigation of the links between hemodynamic parameters and the significance of coronary stenoses.

Keywords Computational flow simulation · Coronary arteries · Hemodynamics

\section{Introduction}

In daily clinical routine, coronary artery disease (CAD), defined as a diameter stenosis larger than $50 \%$ on coronary angiograms, is usually considered to be severe enough to cause myocardial ischemia and, therefore, is regarded to be a candidate for revascularization procedures. As a corollary, mismatch between the detection of ischemia using myocardial perfusion measurements and angiographic results has usually been attributed to the inherent inaccuracies of the non-invasive tools. However, a number of studies have indicated that the simple mechanistic concept of diameter reduction in epicardial coronary arteries leading to myocardial ischemia is incomplete $[1,2]$. Current data, rather, suggests that coronary atherosclerosis is a precondition but may not itself be sufficient to produce ischemic heart disease, and that factors such as the pathobiology of the plaque, the development of collateral circulation, and coronary blood flow play an additional and crucial role in the pathophysiology of myocardial ischemia [3]. Because several investigations have reported that the apparent percent stenosis on coronary angiograms shows no correlation with hemodynamic measurements of blood flow $[1,4]$, the assessment of hemodynamic parameters in adjunct to coronary artery morphology appears intriguing. Moreover, increasing evidence has accumulated that 
hemodynamic factors such as wall pressure and wall shear stress (WSS) promote the process of atherosclerotic plaque formation $[5,6]$.

Hemodynamic flow assessment in coronary arteries is usually performed with intravascular Doppler ultrasound by measuring local velocities [6]. Even if these data enable a hemodynamic characterization of stenosis severity, the introduction of an ultrasound-catheter into the lumen is an invasive procedure, leads to flow disturbances, and the results of such measurements are, therefore, often difficult to interpret [7]. An alternative means for invasive flow measurements is presented by the calculation of models in which blood flow can be virtually simulated, a method that is called computational fluid dynamics (CFD). In fact, several in vitro studies [8-13] and some in vivo investigations $[10,12,14]$ have shown that CFD allows reliable physiologic blood flow simulation and measurements of WSS, wall pressure, and mass flow. A requisite for obtaining reliable results from coronary CFD is to use exact anatomical models [10], which, today, are provided by multi-detector row computed tomography (CT). The three-dimensional (3D) reconstruction of coronary arteries from CT datasets has been shown to be more accurate than corresponding 3D reconstructions obtained from conventional angiography combining two simultaneously captured two-dimensional (2D) views $[10,15]$. The purpose of this study was to simulate pulsatile blood flow in coronary arteries using CFD based on geometric models from CT datasets in five patients and to measure the WSS, wall pressure, and mass flow and visualize flow patterns both in the absence and presence of coronary plaques.

\section{Materials and methods}

\section{Computed tomography data acquisition}

Five patients (two female, three male; mean age $57.3 \pm$ 7.9 years; age range $47-66$ years) underwent cardiac CT on a 16-detector row scanner (Sensation 16, Siemens Medical Solutions, Forchheim, Germany) using the following parameters: detector collimation $16 \times 0.75 \mathrm{~mm}$, gantry rotation time $0.37 \mathrm{~s}$, pitch 0.38 , tube potential $120 \mathrm{kV}$, tube current time product $400 \mathrm{mAs}$. A bolus of $150 \mathrm{ml}$ iodinated contrast material (iodixanol, Visipaque 320, $320 \mathrm{mg} / \mathrm{ml}$, Amersham Health, Buckinghamshire, UK) followed by $30 \mathrm{ml}$ saline solution was continuously injected into a right antecubital vein via a $18-20$-gauge catheter at a flow rate of $5 \mathrm{ml} / \mathrm{s}$. Bolus tracking was performed with a region of interest (ROI) in the ascending aorta, and image acquisition was automatically started $5 \mathrm{~s}$ after signal attenuation reached a threshold of $140 \mathrm{HU}$. All patients received $\beta$-blockers as part of their baseline medication at the time of the CT scan; no additional $\beta$-blockers were administered prior to CT.
Synchronized to the electrocardiogram (ECG), CT data sets were retrospectively reconstructed throughout the cardiac cycle in 5\% steps of the R-R interval with a slice thickness of $1 \mathrm{~mm}$ and an increment of $0.5 \mathrm{~mm}$ using a medium soft-tissue convolution kernel (B30f). The percent phase indicates the beginning of the respective interval. The adaptive cardio volume approach was used for image reconstruction [16] and ECG-pulsing was applied to reduce radiation exposure [17]. Similar to a previous study [18], the reconstruction phase providing the best image quality with the lowest degree of motion artifacts was determined by two radiologists in consensus and was used for further post-processing. The study protocol was approved by the local ethics committee and written informed consent was obtained from all patients.

\section{Geometric reconstruction}

Axial CT images were digitally processed to extract geometrical contours representing the coronary vessel walls. The lumen of the coronary arteries of the five patients was semi-automatically segmented using a commercially available software package (Amira 3.1, TGS, Belgium). In regions of reduced arterial opacification, segmentation was manually complemented. The outflows (i.e., the end of the branches) and inflows (i.e., the ostium) of the vessels were separately marked to allow the definition of boundary conditions. As a next step, an unstructured surface mesh of triangles was generated covering the segmented volume using the marching cube algorithm [19]. Manual smoothing and low-pass spatial filtering was then applied to further reduce fine-scale surface irregularities. The final model depicted the real 3D geometry of the coronary arteries (Fig. 1). Geometric computational models were subsequently built with computational meshes of $800,000-1,000,000$ tetrahedral cells for the entire models, representing a spatial resolution of $0.15 \mathrm{~mm}$. The number of elements per cross-section was 150 to 200 , depending on the vessel diameter. Only one model per patient was reconstructed. This model was used for pulsatile blood flow simulations for the entire cardiac cycle.

\section{Model assumptions and boundary conditions}

The flow for the simulation was considered transient, 3D, incompressible, and laminar (based on the low Reynolds number of approximately 300 for small vessels) [11]. Corresponding to standard values from the literature [20], the blood was assumed to be Newtonian with a viscosity of $0.0037 \mathrm{Pas}$ and a density of $1060 \mathrm{~kg} / \mathrm{m}^{3}$. The walls were taken as solid and stiff, and a zero-velocity boundary condition was assumed for the walls, corresponding to a no-slip condition. Compared to other flow simulations, it 
Fig. 1 Curved multi-planar reformation (top) and geometric model after semi-automatic segmentation (bottom) of the left coronary artery in a patient with no evidence of atherosclerosis (left) and in a patient with severe atherosclerotic wall changes (right)
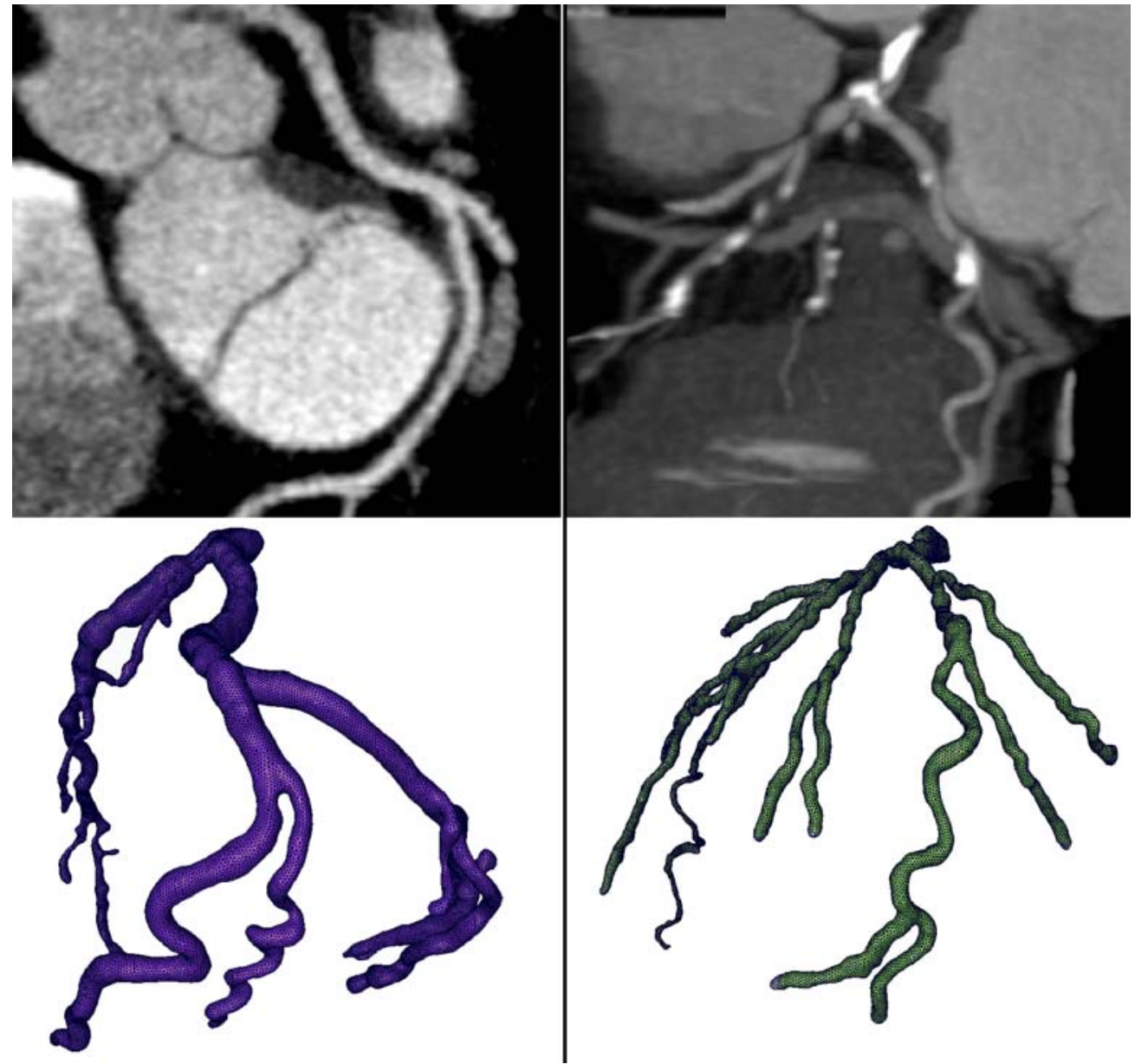

was renounced to elongate the inlet part, which is usually done for a full development of the fluid with a parabolic velocity shape. Therefore, the inlet is identical to the real coronary ostium and every point at the inlet has identical flow parameters, including direction and velocity. The flow velocity profile at the different inlets was based on standard data reflecting the physiologically pulsatile, biphasic blood flow from the ascending aorta into the coronary arteries $[21,22]$ (Fig. 2).

\section{Computational fluid dynamics}

A threshold value of $0.5 \%$ has been adopted for the maximum permissible change in the numerically calculated values of wall pressure, WSS, and flow velocities within the flow domain. The FIDAP software (Fluent Corp., Darmstadt, Germany) was used to carry out the simulation by solving Navier-Stokes equations. This software has been evaluated for steady flow in a previous study and has been employed for the simulation of flow in the aorta $[23,24]$. The calculated flow variables were flow velocities, WSS, and wall pressure. The FIELDVIEW software (Version 11.0, Intelligent Light, Lyndhurst, NJ) was used for the visualization of flow patterns, the quantification of WSS and wall pressure, and for the measurement of mass flow at selected sites.

\section{Results}

Mean heart rates during CT scanning in the five patients were $64 \pm 11 \mathrm{bpm}$ (range 52-78 bpm). The percent phase providing the best image quality was found between 45$60 \%$ of the R-R interval for the right coronary artery (RCA) and between $55-70 \%$ for the left main artery (LMA), left anterior descending artery (LAD), and left circumflex artery (LCX). All coronary arteries larger than $1.5-\mathrm{mm}$ vessel diameter could be adequately visualized (see example in Fig. 1). Three patients showed atherosclerotic wall changes of their coronary arteries with five significant stenoses (i.e., $>50 \%$ luminal diameter reduction) in four segments, that were later confirmed by conventional invasive angiography. Two patients had no evidence of coronary artery disease (i.e., no fibrous, lipomatous, or calcified plaques, no evidence of positive remodeling, and no diameter stenoses). 
Fig. 2 Flow velocities throughout one cardiac cycle used as the input function at the ostium of the left main artery $(L M A)$ and right coronary artery $(R C A)$. Values are based on measurements from the literature $[21,22]$
Input function for pulsatile blood flow

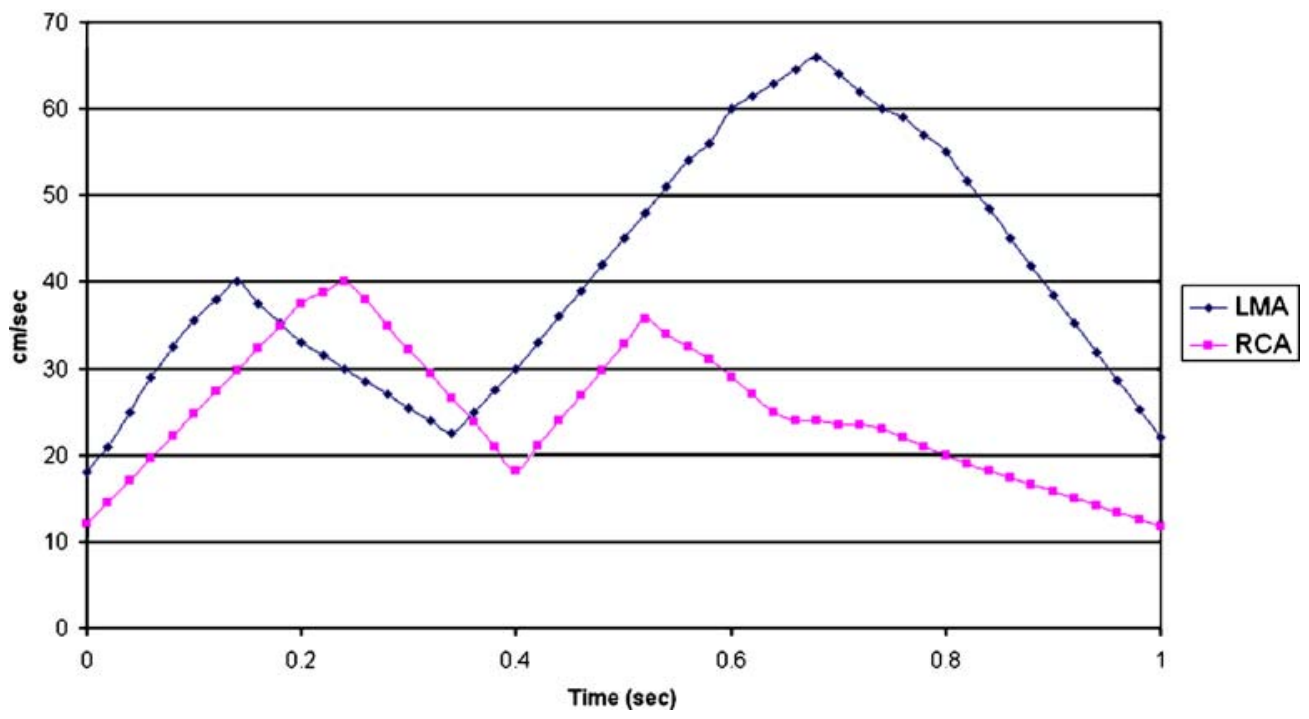

Mass flow

The mean mass flow, measured after simulation, through the left and right coronary artery in the two patients without arteriosclerosis was $3.55 \mathrm{ml} / \mathrm{s}$ (range $3.21-3.71 \mathrm{ml} / \mathrm{s}$ ) and $2.97 \mathrm{ml} / \mathrm{s}$ (range $2.51-3.31 \mathrm{ml} / \mathrm{s}$ ), respectively, whereas the mean mass flow through the left and right coronary artery in the three patients with arteriosclerosis was $3.16 \mathrm{ml} / \mathrm{s}$ (range $2.91-3.36 \mathrm{ml} / \mathrm{s}$ ) and $2.41 \mathrm{ml} / \mathrm{s}$ (range $2.25-2.71 \mathrm{ml} / \mathrm{s}$ ), respectively. Quantification of mass flow through the LMA, LAD, and LCX, and the instantaneous history of blood flux through each of the outlets in a patient without evidence of coronary atherosclerosis and in a patient with significant stenosis at the origin of the LAD are demonstrated in Fig. 3a. The distribution of pulsatile flow could be determined by using this mass flow curve at each time-step of the cardiac cycle. In the patient with coronary arteriosclerosis, the mass flow calculations revealed that about $67 \%$ of the total blood inflow was directed through the LCX, about $28 \%$ through the $\mathrm{LAD}$, and $5 \%$ through the ramus intermedius. The high percentage of mass flow through the LCX can be explained by the significant stenosis at the origin of the LAD. In contrast, the mass flow through the LAD and LCX was almost equal (LAD 46\%, LCX 54\%) in the patient without significant stenosis. The effects of pulsatility damped from the origin of the right and left coronary artery towards distal segments, as the flow progressed further downstream and eventually reached a quasi steady capillary bed value.

Wall pressure and wall shear stress

The change of WSS throughout the cardiac cycle highly correlated to flow velocities. The WSS characterizes the forces that longitudinally act on the vessel wall. These forces were high when the blood flow parallel to the wall was fast. The maximum WSS spatial variation was approximately $15.8 \mathrm{~Pa}$, whereas the corresponding maximum wall pressure drop reached $188 \mathrm{~Pa}$. The value of the wall pressure drop is a fair estimate of the pressure head needed to drive the flow through the various branches of the coronary tree. The existence of a stenosis increased the required pressure difference for an identical amount of blood flow. The average WSS ranged from $0.01 \mathrm{~Pa}$ to $1.63 \mathrm{~Pa}$ for minimum and maximum inflow, respectively. These values were within the baseline value of $2 \mathrm{~Pa}$ that were suggested for most arteries in various species [25]. In every patient, the wall pressure decreased towards the periphery of the coronary artery tree. It gradually decreased in non-atherosclerotic segments, whereas the wall pressure was slightly elevated in immediate pre-stenotic segments due to the funnel-like geometry. The wall pressure dropped inside the stenoses as blood flow velocity increased (Law of Bernoulli). In the post-stenotic segments, the wall pressure continued to gradually drop towards the most distal segments (Fig. 3b).

Comparing hemodynamic changes throughout a cardiac cycle between a normal (Fig. 4) and an atherosclerotic vessel (Fig. 5) revealed that the arteriosclerotic wall contains more regions with WSS variations. Whereas in normal coronary arteries the WSS remained low during phases of high flow velocity, the WSS was elevated in arteriosclerotic vessels, even at low flow velocities. Parallel to the changes of WSS, the flow pattern was more variable and inconsistent in arteriosclerotic vessels. Stenoses and post-stenotic dilatations have led to acceleration and rapid deceleration, respectively, including a distortion of flow. No vortices were found in any atherosclerotic vessel. In coronary segments with no evidence of coronary artery disease, small areas of increased WSS were found, which may indicate regions of early plaque formation initializing 
a

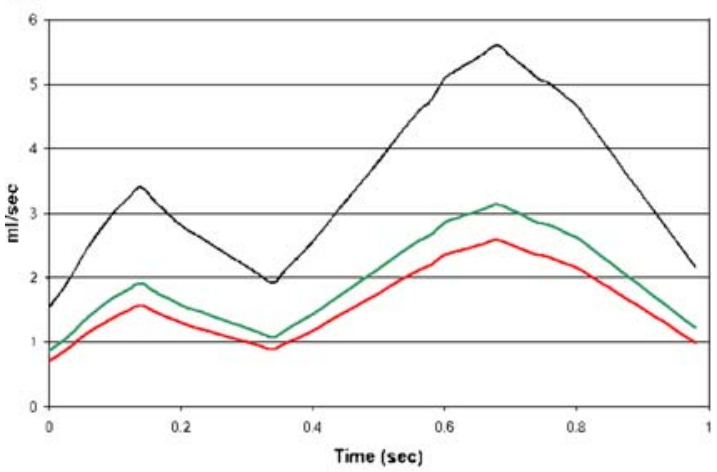

b
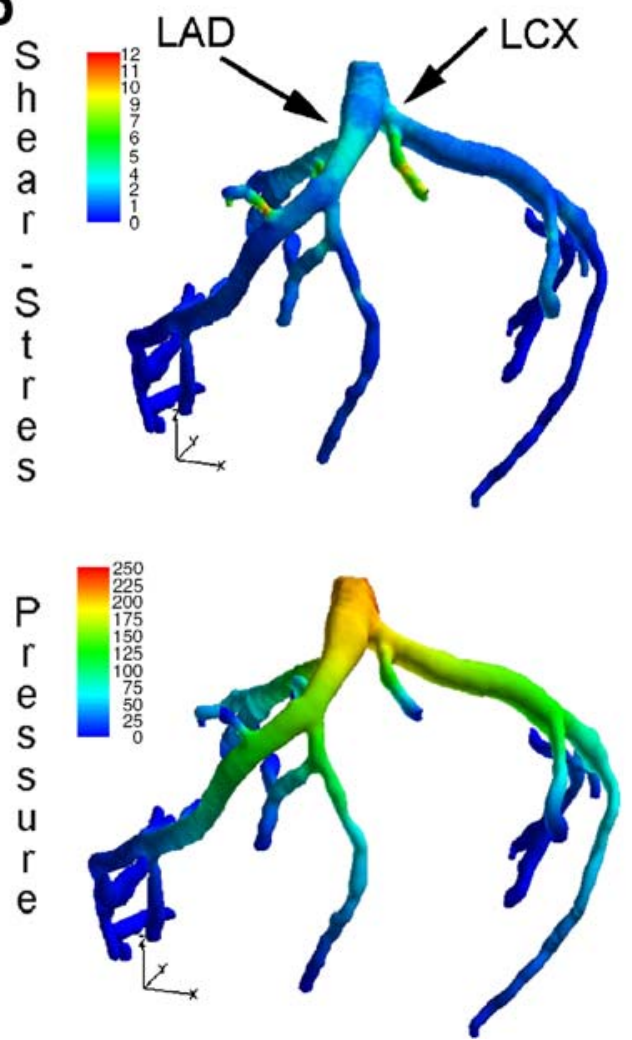

Mass-flow in atherosclerotic vessel
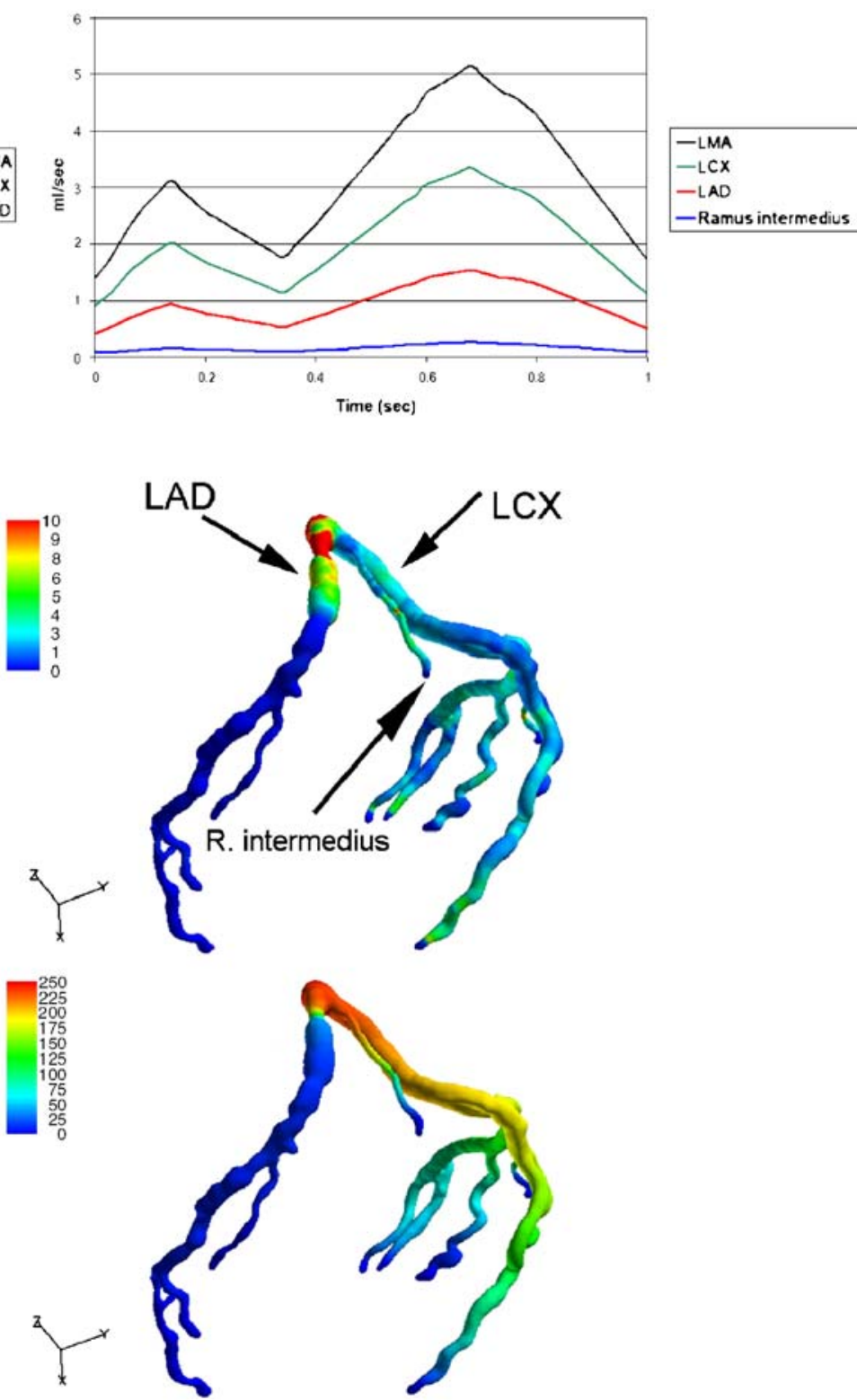

Fig. 3 a Measured mass flow values (in $\mathrm{ml}$ per second) at defined points in the left main artery $(L M A)$, left anterior descending artery $(L A D)$, left circumflex artery $(L C X)$, and in the ramus intermedius in a patient without atherosclerosis (left) and a patient with atherosclerosis (right). The mass flow shows no significant difference between the LAD and LCX in the normal coronary arteries. In the patient with significant stenosis at the origin of the LAD, a reduced mass flow distal of the stenosis and a higher absolute mass flow value in the LCX is demonstrated. b Color-coded wall shear stress $(\mathrm{Pa})$ and wall pressure $(\mathrm{Pa})$ in the same two patients with non-

the vicious circle of arteriosclerosis. However, no early atheromas could be visualized in these areas, which may be due to the limited spatial and temporal resolution of the 16detector row CT scanner used in this study. atherosclerotic coronary arteries (left) and in the patient with significant stenosis at the origin of the left anterior descending artery $(L A D)($ right $)$ at mid-diastole. In the normal vessel, the wall pressure gradually drops towards distal segments and no region with high wall shear stress is found. In the atherosclerotic vessel, the wall pressure drops at the site of the stenosis and wall shear stress significantly increases. Some additional areas of elevated wall shear stress correlate to atherosclerotic segments. Quantitative values can be assessed by reference to the scales

\section{Discussion}

The invasiveness and the risk of conventional coronary angiography forced clinicians to conceive non-invasive tests to optimize the selection of candidates for catheter 


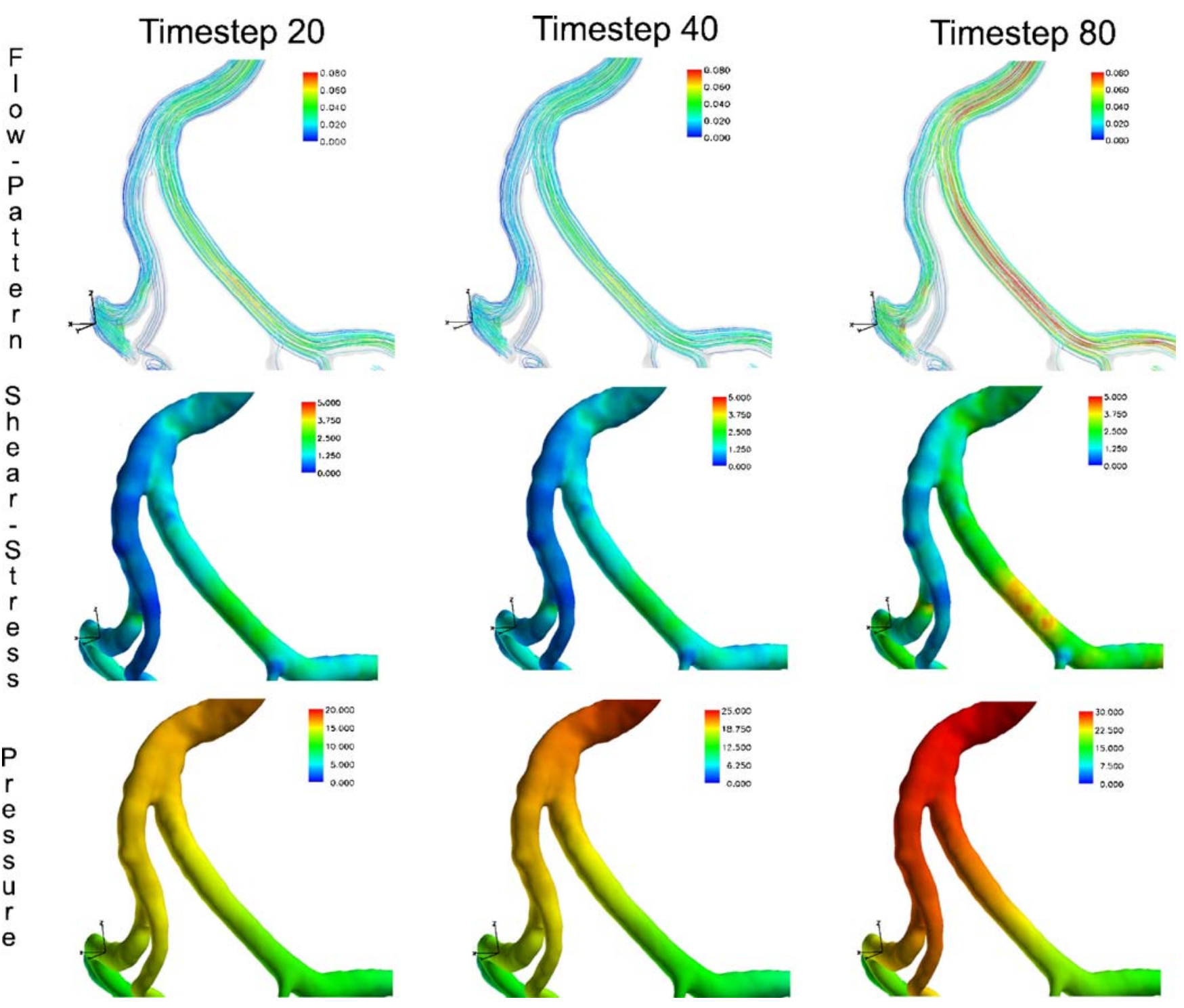

Fig. 4 Velocity-coded streamlines $(\mathrm{m} / \mathrm{s})$, wall shear stress (WSS, $\mathrm{Pa})$, and wall pressure $(\mathrm{Pa})$ in a non-atherosclerotic coronary bifurcation at three different time-steps of the cardiac cycle. The flow pattern is smooth and the wall shear stress remains low, even at high velocities. Note the small foci of elevated WSS in the middle segment of the left circumflex artery $(L C X)$, possibly indicating regions of early atherosclerotic intimal changes. The wall pressure gradually decreases. Quantitative values can be assessed by reference to the scales angiography. Through the use of these non-invasive methods, knowledge has been accumulated which indicated that the detection of myocardial ischemia provides independent and complementary information to coronary artery morphology [26], that patients with less than 50\% diameter stenoses may be at relatively high risks of developing clinical events [27], and that the angiographic degree of stenosis is a poor predictor of subsequent culprit lesions [28]. Therefore, the degree of epicardial stenosis represents only one factor responsible for a reduction in coronary blood flow reserve in patients with clinical symptoms, and a stenosis incapable of producing angina in one patient may result in severe functional limitation in another [29]. Nowadays, multi-detector row CT coronary angiography provides the most accurate non-invasive means to visualize and characterize the epicardial coronary artery tree with sensitivity values for the detection of coronary stenoses approaching those of the invasive method [30-33]. Our study demonstrates, for the first time, that incorporating into the structural information of CT the parameters characterizing coronary blood flow has become feasible with aid of CFD. This might represent the first step for closing the gap 


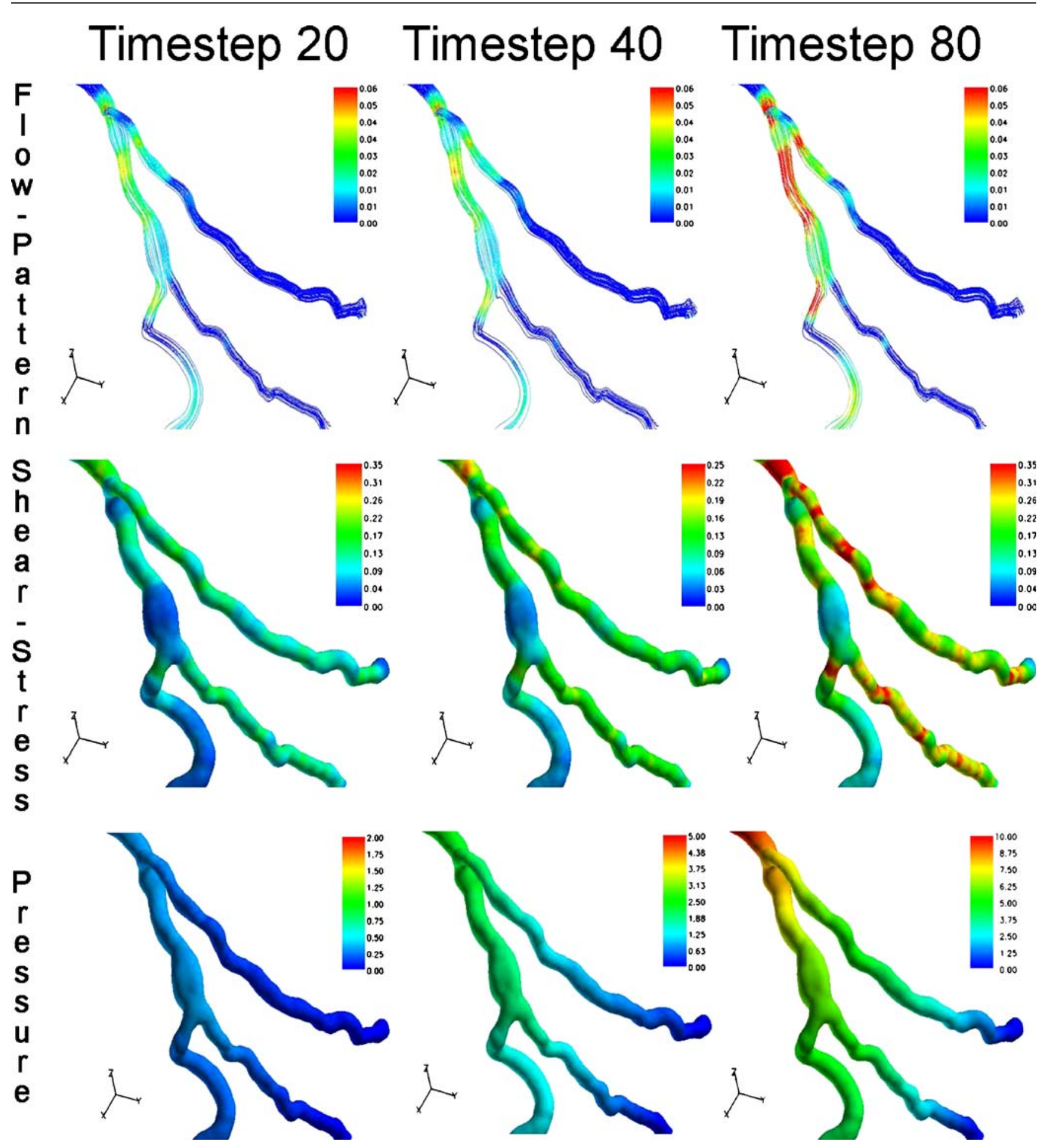

Fig. 5 Velocity-coded streamlines $(\mathrm{m} / \mathrm{s})$, WSS $(\mathrm{Pa})$, and wall pressure $(\mathrm{Pa})$ in an atherosclerotic bifurcation at three different timesteps of the cardiac cycle. The flow pattern is turbulent and distorted, but no vortices are found. There are many regions of elevated wall shear stress correlating either to stenotic segments or to irregular vessel geometry caused by atherosclerosic plaques. The wall pressure gradually decreases and is not significantly influenced by vessel geometry. Quantitative values can be assessed by reference to the scales 
between pure coronary artery morphology and its functional consequence on the myocardium.

Experimental evidence suggests that hemodynamic factors are important in the initiation and progression of atherosclerosis $[5,34,35]$. However, the exact role of the individual parameters could not yet be defined. Conflicting evidence exists with regards to whether low or high WSS may be the initiator of atherosclerosis formation. On the one hand, atherosclerotic plaques have shown to consistently and non-randomly develop in areas of low WSS at arterial bifurcations [36, 37], while areas with higher WSS are relatively protected from plaque development [38]. Mechanisms that are responsible for the association between low WSS and atheroma formation have been suggested by several authors, including the modulation of endothelial function and structure, the regulation of gene expression implicated in the atherogenic process [39, 40], the modification of bulk transport of lipid $[5,41]$, and the promotion of monocyte adhesion to the endothelium [42]. In contrast, high WSS has been proposed from in-vitro studies as a cause of local endothelial injury [43] and it has been shown that artificial stenoses produce platelet activation (i.e., a precursor to thrombus formation) at high WSS values [44]. Therefore, the WSS rate might be a better indicator to estimate the risk of arteriosclerosis.

The main function of wall pressure representing a map of the pressure inside the coronary artery is to push the blood into the capillaries and facilitate diffusion into the myocardium. In all patients of this study, the wall pressure decreased towards the periphery of the coronary artery tree with elevated pressure drops in stenotic segments. The increased pressure drop in stenoses reflects the elevated energy needed to drive the flow through these regions. As shown in atherosclerotic coronary arteries, regions of flow acceleration were associated with high WSS. Relating our CFD results to coronary artery morphology, the location of atherosclerotic plaques correlated well with the regions of high WSS. These results indicate that CFD offers a noninvasive means for an in-vivo validation of the abovementioned experimental evidence in coronary arteries of patients.

Highly accurate anatomy for the generation of geometric models is a principal requirement to perform reliable flow simulations and to make assumptions about mass flow, WSS, and wall pressure. With the advent of 64-slice CT [45] and the newest development of dual-source CT [46], further improvements with regards to temporal and spatial resolution have been made that will allow an even more accurate depiction of coronary artery morphology and pathology. On the other hand, parameters such as move- ment of the wall and of the adjacent perivascular soft tissue or parameters of blood rheology that might also influence flow characteristics still cannot be adequately simulated.

The calculated mass flow gives an idea about the distribution of blood volume throughout the entire coronary artery system. These results are influenced by the caliber of the vessels. Other factors such as myocardial contraction were not taken into account. Therefore, the absolute quantitative results are not yet suitable for exact perfusion measurements.

The following study limitations have to be acknowledged. First, 16-detector row CT does not offer the best available image quality for imaging coronary arteries as compared to newer scanner technology. In addition, the geometric data for CFD was obtained from a single reconstruction time-point in the early to mid-diastolic phase of the cardiac to simulate pulsatile blood flow throughout the entire cardiac cycle and the vessel contours and diameters might be different at other reconstruction time-points. Second, assumptions concerning in- and outflow have been made which may be different under pathologic conditions. Third, heart movement and the changing pressure at the inner wall of the vessel due to muscle tension cannot be simulated yet and was, therefore, not included in the present calculations. Moreover, the arterial wall was simplified as being stiff, thus, results might differ in elastic models of the coronary artery wall. Fourth, only CFD simulations with a steady blood flow in the aorta have been validated so far [23]. Finally, numerical simulation of blood flow is labor intensive and time consuming. However, future methodological and software development should help to enable the application of CFD analysis in daily clinical routine.

In conclusion, our study demonstrates that the simulation of pulsatile blood flow is feasible in-vivo in coronary arteries of patients with geometric data obtained from multi-detector row CT. CFD analysis allows the characterization of normal and abnormal hemodynamics in coronary arteries and demonstrates rises of WSS within stenosic segments. The methodology applied in this study may provide the basis for future investigation and the validation of causal links between hemodynamic flow variables and myocardial ischemia beyond the assessment of coronary artery morphology alone.

Acknowledgments This paper was supported by the National Center of Competence in Research for Computer Aided and Image Guided Medical Interventions (NCCR CO-ME) of the Swiss National Science Foundation. 


\section{References}

1. Kern MJ, Meier B (2001) Evaluation of the culprit plaque and the physiological significance of coronary atherosclerotic narrowings. Circulation 103(25):3142-3149

2. Sambuceti G (2005) Differences and similarities between coronary atherosclerosis and ischaemic heart disease: implications for cardiac imaging. Eur $\mathbf{J}$ Nucl Med Mol Imaging 32(4):385-388

3. Di Carli M, Czernin J, Hoh CK, Gerbaudo VH, Brunken RC, Huang SC, Phelps ME, Schelbert HR (1995) Relation among stenosis severity, myocardial blood flow, and flow reserve in patients with coronary artery disease. Circulation 91(7):1944-1951

4. White CW, Wright CB, Doty DB, Hiratza LF, Eastham CL, Harrison DG, Marcus ML (1984) Does visual interpretation of the coronary arteriogram predict the physiologic importance of a coronary stenosis? N Engl J Med 310 (13):819-824

5. Caro CG, Fitz-Gerald JM, Schroter RC (1971) Atheroma and arterial wall shear. Observation, correlation and proposal of a shear dependent mass transfer mechanism for atherogenesis. Proc R Soc Lond B Biol Sci 177 (46):109-159

6. Pijls NH, De Bruyne B, Bech GJ, Liistro F, Heyndrickx GR, Bonnier HJ, Koolen JJ (2000) Coronary pressure measurement to assess the hemodynamic significance of serial stenoses within one coronary artery: validation in humans. Circulation 102(19):2371-2377

7. Krams R, Wentzel JJ, Cespedes I, Vinke R, Carlier S, van der Steen AF, Lancee CT, Slager CJ (1999) Effect of catheter placement on 3-D velocity profiles in curved tubes resembling the human coronary system. Ultrasound Med Biol 25(5):803-810

8. Shalman E, Rosenfeld M, Dgany E, Einav S (2002) Numerical modeling of the flow in stenosed coronary artery. The relationship between main hemodynamic parameters. Comput Biol Med 32(5):329-344

9. Giannoglou GD, Soulis JV, Farmakis TM, Farmakis DM, Louridas GE (2002) Haemodynamic factors and the important role of local low static pressure in coronary wall thickening. Int $\mathrm{J}$ Cardiol 86(1):27-40
10. Berthier B, Bouzerar R, Legallais C (2002) Blood flow patterns in an anatomically realistic coronary vessel: influence of three different reconstruction methods. J Biomech 35(10):1347-1356

11. Santamarina A, Weydahl E, Siegel JM Jr, Moore JE Jr (1998) Computational analysis of flow in a curved tube model of the coronary arteries: effects of timevarying curvature. Ann Biomed Eng 26 (6):944-954

12. Boutsianis E, Dave H, Frauenfelder T, Poulikakos D, Wildermuth S, Turina M, Ventikos Y, Zund G (2004) Computational simulation of intracoronary flow based on real coronary geometry. Eur J Cardiothorac Surg 26(2):248-256

13. Andersson HI, Halden R, Glomsaker T (2000) Effects of surface irregularities on flow resistance in differently shaped arterial stenoses. J Biomech 33 (10):1257-1262

14. Birchall D, Zaman A, Hacker J, Davies $\mathrm{G}$, Mendelow D (2006) Analysis of haemodynamic disturbance in the atherosclerotic carotid artery using computational fluid dynamics. Eur Radiol 16(5):1074-1083

15. Sarwal A, Dhawan AP (2001) Three dimensional reconstruction of coronary arteries from two views. Comput Methods Programs Biomed 65(1):25-43

16. Flohr T, Ohnesorge B (2001) Heart rate adaptive optimization of spatial and temporal resolution for electrocardiogram-gated multislice spiral CT of the heart. J Comput Assist Tomogr 25 (6):907-923

17. Jakobs TF, Becker CR, Ohnesorge B, Flohr T, Suess C, Schoepf UJ, Reiser MF (2002) Multislice helical CT of the heart with retrospective ECG gating: reduction of radiation exposure by ECG-controlled tube current modulation. Eur Radiol 12(5):1081-1086

18. Husmann L, Alkadhi H, Boehm T, Leschka S, Schepis T, Koepfli P, Desbiolles L, Marincek B, Kaufmann PA, Wildermuth S (2006) Influence of cardiac hemodynamic parameters on coronary artery opacification with 64slice computed tomography. Eur Radiol 16(5):1111-1116

19. Lorensen WE, Cline HE (1987) Marching cubes: a high-resolution 3D surface construction algorithm. Comput Graph 21(4):163-169

20. Berger SA, Goldsmith EW, Lewis ER (2000) Introduction to bioengineering. Oxford University Press, Oxford, UK

21. Canver CC, Dame NA (1994) Ultrasonic assessment of internal thoracic artery graft flow in the revascularized heart. Ann Thorac Surg 58(1):135-138
22. Drost C (2002) On/off pump graft patency assessment. Transonic Systems Inc., Ithaca, New York

23. Frauenfelder T BE, Ventikos Y, Marincek B, Wildermuth S (2003) Comparison of numerical and experimental flow simulation in patient-specific 3D-models of abdominal aortic aneurysm. In: Annual Meeting and Postgraduate Course of the Cardiovascular and Interventional Radiological Society of Europe-CIRSE., book of abstracts 43.2 .7

24. Frauenfelder T, Lotfey M, Boehm T, Wildermuth S (2006) Computational fluid dynamics: hemodynamic changes in abdominal aortic aneurysm after stent-graft implantation. Cardiovasc Intervent Radiol 29(4):613-623

25. $\mathrm{Ku} \mathrm{DN} \mathrm{(1997)} \mathrm{Blood} \mathrm{flow} \mathrm{in} \mathrm{arteries.}$ Annu Rev Fluid Mech 29:399-434

26. Hachamovitch R, Hayes S, Friedman JD, Cohen I, Shaw LJ, Germano G, Berman DS (2003) Determinants of risk and its temporal variation in patients with normal stress myocardial perfusion scans: what is the warranty period of a normal scan? J Am Coll Cardiol 41(8):1329-1340

27. Little WC, Constantinescu M, Applegate RJ, Kutcher MA, Burrows MT, Kahl FR, Santamore WP (1988) Can coronary angiography predict the site of a subsequent myocardial infarction in patients with mild-to-moderate coronary artery disease? Circulation 78(5 Pt 1):11571166

28. Fuster V, Fallon JT, Badimon JJ, Nemerson Y (1997) The unstable atherosclerotic plaque: clinical significance and therapeutic intervention. Thromb Haemost 78(1):247-255

29. Topol EJ, Nissen SE (1995) Our preoccupation with coronary luminology. The dissociation between clinical and angiographic findings in ischemic heart disease. Circulation 92(8):2333-2342

30. Leschka S, Alkadhi H, Plass A, Desbiolles L, Grunenfelder J, Marincek B, Wildermuth S (2005) Accuracy of MSCT coronary angiography with 64 slice technology: first experience. Eur Heart J 26(15):1482-1487

31. Raff GL, Gallagher MJ, O'Neill WW, Goldstein JA (2005) Diagnostic accuracy of noninvasive coronary angiography using 64-slice spiral computed tomography. J Am Coll Cardiol 46 (3):552-557 
32. Leber AW, Knez A, von Ziegler F, Becker A, Nikolaou K, Paul S, Wintersperger B, Reiser M, Becker CR, Steinbeck G, Boekstegers P (2005) Quantification of obstructive and nonobstructive coronary lesions by 64-slice computed tomography: a comparative study with quantitative coronary angiography and intravascular ultrasound. J Am Coll Cardiol 46(1):147-154

33. Mollet NR, Cademartiri F, van Mieghem CA, Runza G, McFadden EP, Baks T, Serruys PW, Krestin GP, de Feyter PJ (2005) High-resolution spiral computed tomography coronary angiography in patients referred for diagnostic conventional coronary angiography. Circulation 112(15):2318-2323

34. Cunningham KS, Gotlieb AI (2005) The role of shear stress in the pathogenesis of atherosclerosis. Lab Invest 85(1):9-23

35. Perktold K, Hofer M, Rappitsch G, Loew M, Kuban BD, Friedman MH (1998) Validated computation of physiologic flow in a realistic coronary artery branch. J Biomech 31(3):217-228
36. DeBakey ME, Lawrie GM, Glaeser DH (1985) Patterns of atherosclerosis and their surgical significance. Ann Surg 201(2):115-131

37. Zarins CK, Giddens DP, Bharadvaj BK, Sottiurai VS, Mabon RF, Glagov S (1983) Carotid bifurcation atherosclerosis. Quantitative correlation of plaque localization with flow velocity profiles and wall shear stress. Circ Res 53 (4):502-514

38. Caro CG, Fitz-Gerald JM, Schroter RC (1969) Arterial wall shear and distribution of early atheroma in man. Nature 223(211):1159-1160

39. Nagel T, Resnick N, Dewey CF Jr, Gimbrone MA Jr (1999) Vascular endothelial cells respond to spatial gradients in fluid shear stress by enhanced activation of transcription factors. Arterioscler Thromb Vasc Biol 19 (8):1825-1834

40. Cho A, Mitchell L, Koopmans D, Langille BL (1997) Effects of changes in blood flow rate on cell death and cell proliferation in carotid arteries of immature rabbits. Circ Res 81(3):328-337

41. Deng X, Stroman PW, Guidoin R (1996) Theoretical modelling of the release rate of low-density lipoproteins and their breakdown products at arterial stenoses. Clin Invest Med 19(2):83-91

42. Mohan S, Mohan N, Valente AJ, Sprague EA (1999) Regulation of low shear flow-induced HAEC VCAM-1 expression and monocyte adhesion. Am J Physiol 276(5 Pt 1):C1100-C1107
43. Fry DL (1969) Certain histological and chemical responses of the vascular interface to acutely induced mechanical stress in the aorta of the dog. Circ Res 24(1):93-108

44. Holme PA, Orvim U, Hamers MJ, Solum NO, Brosstad FR, Barstad RM, Sakariassen KS (1997) Shear-induced platelet activation and platelet microparticle formation at blood flow conditions as in arteries with a severe stenosis. Arterioscler Thromb Vasc Biol 17(4):646-653

45. Flohr TG, Stierstorfer K, Ulzheimer S, Bruder H, Primak AN, McCollough $\mathrm{CH}$ (2005) Image reconstruction and image quality evaluation for a 64-slice CT scanner with z-flying focal spot. Med Phys 32(8):2536-2547

46. Flohr TG, McCollough $\mathrm{CH}$, Bruder $\mathrm{H}$, Petersilka M, Gruber K, Suss C, Grasruck M, Stierstorfer K, Krauss B, Raupach R, Primak AN, Kuttner A, Achenbach S, Becker C, Kopp A, Ohnesorge BM (2006) First performance evaluation of a dual-source CT (DSCT) system. Eur Radiol 16(2):256-268 